\title{
Control of ovarian steroidogenesis by insulin-like peptides in the blowfly (Phormia regina)
}

\author{
G Manière, I Rondot, E E Büllesbach ${ }^{1}$, F Gautron, E Vanhems \\ and J P Delbecque

\begin{abstract}
Université Bordeaux I, Laboratoire de Neuroendocrinologie des Insectes, Avenue des Facultés, F-33405 Talence Cedex, France
${ }^{1}$ Medical University of South Carolina, Department of Biochemistry and Molecular Biology, 171 Ashley Avenue, Charleston, South Carolina 29425, USA

(Requests for offprints should be addressed to J P Delbecque who is now at Université Bordeaux I, Laboratoire de Neurobiologie des Réseaux, CNRS UMR 5816, Avenue des Facultés, F-33405 Talence Cedex, France; Email: jp.delbecque@Inr.u-bordeaux1.fr)

(G Manière is now at Université de Bourgogne, CNRS UMR 5548 'Développement Communication chimique', 6 Boulevard Gabriel, F-21000 Dijon, France) F-33405 Talence Cedex, France)

(I Rondot is now at Université Bordeaux I, Laboratoire de Neurobiologie des Réseaux, CNRS UMR 5816, Avenue des Facultés, F-33405 Talence Cedex, France)
\end{abstract} \\ (F Gautron is now at Université Bordeaux I, Laboratoire des Facteurs de Croissance et de la Différenciation Cellulaire, INSERM EPI-0113, Avenue des Facultés,
}

\begin{abstract}
This study investigated the ability of insulin and of insect insulin-like peptides (ILPs) to stimulate ovarian steroidogenesis in the blowfly Phormia regina. Bovine insulin was active on ovaries isolated in vitro, which showed an age-dependent sensitivity; this peptide progressively stimulated steroidogenesis in ovaries isolated from the third day after adult molt, but not in younger ones, and had maximal activity after the fifth day. This stimulatory effect was observed equally from females reared in the presence or in the absence of males, excluding a regulatory effect of mating. The mode of action of insulin in blowflies did not involve cAMP, but triggered a specific and well-conserved transduction cascade. In particular, a peroxovanadium compound, known to activate specifically the insulin receptor in mammals, also stimulated blowfly ovarian steroidogenesis in vitro. Conversely, chemicals known to inhibit the mammalian insulin receptor or downstream elements of its signaling pathway, such as LY294002, an
\end{abstract}

inhibitor of phosphatidylinositol 3-kinase (PI3K), were able to prevent the steroidogenic action of bovine insulin on fly ovaries. Extracts from the median neurosecretory cells (MNCs) of blowfly brains, which are known to contain endogenous ILPs, stimulated ovarian steroidogenesis very efficiently and were also sensitive to inhibition by LY294002. These experiments indicated the involvement of PI3K in the mode of action of MNC extracts and substantiated that their endogenous ILPs are involved in the regulation of ovarian steroidogenesis. This conclusion was corroborated by the effects of synthetic bombyxin II, an ILP originating from silkworm MNCs, which also stimulated steroidogenesis in isolated blowfly ovaries. Altogether, these data suggest that insulinlike neurohormones from MNCs play a crucial role as steroidogenic gonadotropins in female flies.

Journal of Endocrinology (2004) 181, 147-156

\section{Introduction}

Peptide gonadotropins that regulate vitellogenesis and oogenesis in insects are generally considered to originate from the median neurosecretory cells (MNCs) of the brain, also known as pars intercerebralis, and to be liberated from the corpora cardiaca neurohemal complex (for review see Girardie 1983, De Loof et al. 2001). The major roles of these neurohormones include the stimulation of ovarian steroidogenesis, leading to the release of ecdysteroids into hemolymph. Indeed, beside their crucial function as molting hormones during immature stages, ecdysteroids also control several important aspects of reproduction in adult insects (for review see Hagedorn
1989). In particular, they are directly involved in the regulation of vitellogenin biosynthesis in the fat body of higher Diptera. Although in other insects this important role is played by a sesquiterpenoid hormone (juvenile hormone), there is some evidence, at least in two species of locusts (Girardie \& Girardie 1996, Girardie et al. 1998), that ecdysteroids still intervene and may be necessary for the onset of vitellogenesis.

Until now, only two unrelated steroidogenic gonadotropins have been identified in two different insect species, ovarian maturating parsin (OMP) in Locusta migratoria (Girardie \& Girardie 1996) and ovarian ecdysteroidogenic hormone $(\mathrm{OEH})$ in Aedes aegypti (Brown et al. 1998). However, such neurohormones have not yet been isolated 
in flies. In particular, no putative homolog has been identified in Drosophila, despite the availability of the complete sequence of its genome (for review see Nässel 2002).

Nevertheless, our previous investigations in the blowfly Phormia regina have shown that at least two different brain factors are involved in the stimulation of ovarian steroidogenesis: the main one indeed originates from MNCs, whereas the other is elaborated in another, as yet unknown, part of the brain. Thus far, these factors have only been distinguished by their mode of action on ovarian steroidogenic cells, more particularly by their relationships with cAMP, the former acting via a cAMP-independent pathway, the latter via a cAMP-dependent one (Manière et al. 2000).

The aim of the present study was to obtain more information on the nature of the MNC factor in blowflies and on its mode of action in ovaries. More particularly, our experiments were designed to examine the hypothesis that this factor could be an insulin-like peptide (ILP). In insects indeed, ILPs are among the major products synthesized by MNCs and are thus considered as true neurohormones (for review see Smit et al. 1998, Claeys et al. 2002, Nässel 2002). In particular, they have been detected in the MNCs of a blowfly species (Duve \& Thorpe 1979, Duve et al. 1979) and of Drosophila (Brogiolo et al. 2001). Variations in the hemolymph concentrations of ILPs have been correlated with the ovarian biosynthesis of ecdysteroids in locusts (Sevala \& Loughton 1992). Bombyxin, an ILP isolated from silkworm brain was found to stimulate steroidogenesis in the molting glands of lepidopteran larvae (Nagasawa et al. 1986) and to have also some unknown role during reproduction, as indicated by the detection of specific receptors in ovaries (Fullbright et al. 1997). Several studies have also demonstrated that ILP receptors and their transduction mechanisms are involved in the control of reproduction in several insect species, in particular the fruitfly (for review see Claeys et al. 2002, Garofalo 2002). The ILP receptor gene is mainly expressed in adult ovaries, particularly in the follicle cells (Fullbright et al. 1997, Graf et al. 1997, Helbling \& Graf 1998, Riehle \& Brown 2002) which are considered as the source of ovarian ecdysteroids (Goltzené et al. 1978, Chavez et al. 2000). More particularly, mutations on the ILP receptor gene in Drosophila provoke deficiencies in ovarian ecdysteroidogenesis ( $\mathrm{Tu}$ et al. 2002). Furthermore, it has been demonstrated that bovine or porcine insulins, as well as pharmacological compounds mimicking the insulin signaling pathway in mammals, are able to stimulate ecdysteroid biosynthesis in the ovaries of female mosquitoes (Graf et al. 1997, Riehle \& Brown 1999).

Until now, however, no direct evidence has been obtained that an insect ILP could really play such a gonadotropic role in an adult insect. The following study was thus undertaken, initially to verify if such a steroidogenic response to mammalian insulin also exists in blowflies and, further, to examine if MNCs could be the source of an insulin-like stimulation of ecdysteroid biosynthesis in ovaries. In this context, we also investigated the effects of a synthetic bombyxin on blowfly steroidogenesis.

\section{Materials and Methods}

\section{Animals}

Last-instar larvae of $P$. regina were purchased from La Verminière de l'Ouest (Tremblay, France) and reared to adulthood in controlled conditions $\left(25^{\circ} \mathrm{C}, 16 \mathrm{~h}\right.$ light: $8 \mathrm{~h}$ darkness cycle). Flies were supplied with sugar and water, a diet preventing oocyte growth and vitellogenesis in females. The flies used in this study were thus only previtellogenic females, generally maintained in the presence of males (except when otherwise stated). (For more details, see Manière et al. 2000).

After anesthesia with $\mathrm{CO}_{2}$, experimental flies were placed on crushed ice and were decapitated immediately. Dissections of brains, MNCs and/or ovaries were performed rapidly under a dissecting microscope, in dry conditions.

\section{Chemicals}

The chemicals used in this study were purchased from Sigma, except $\mathrm{mpV}$ (pic) (monoperoxo(picolinato) oxovanadate $(\mathrm{V})$ ) and HNMPA-(AM) ${ }_{3}$ (hydroxy-2napthalenylmethylphosphonic acid-tris acetoxymethylester) which were obtained from Calbiochem (France Biochem, Meudon). Bombyxin II was synthesized as previously described (Büllesbach 1999). LY294002: 2-(4morpholinyl)-8-phenyl-4H-1-benzopyran-4-one.

\section{In vitro experiments}

Ovaries of the same pair, extirpated under sterile conditions, were rinsed four times with Grace's insect culture medium (Gibco), placed separately in $50 \mu \mathrm{l}$ culture medium into 96 -well plates and incubated at $26 \pm 1{ }^{\circ} \mathrm{C}$, over $1 \mathrm{~h}$ for cAMP experiments and $3 \mathrm{~h}$ or overnight for ecdysteroids.

Our bioassays were performed as previously described (Manière et al. 2000): in general, one ovary from an individual pair was treated and tested for its response, whereas the contralateral ovary was used as its corresponding untreated control. For every new batch of flies, blank experiments were also carried out to verify regularly that the two ovaries from the same pair, incubated separately in medium, secreted the same amounts of ecdysteroids.

MNC extracts were prepared as previously described (Manière et al. 2000): pools of approximately 50 pars 
intercerebralis were homogenized in Grace's insect culture medium and centrifuged (at $6000 \mathrm{~g}$ for $10 \mathrm{~min}$ at $4{ }^{\circ} \mathrm{C}$ ); then the supernatants were filtered through $0 \cdot 2 \mu \mathrm{m}$ sterile cartridges (Millipore).

\section{Immunoassays}

Ecdysteroids were measured as previously described (Manière et al. 2000), with an enzyme immunoassay based on the polyclonal L2 anti-ecdysone antibody (Pascual et al. 1995). Each measurement was made on the conditioned medium of a single ovary, preliminary experiments having shown that isolated previtellogenic ovaries did not contain significant amounts of ecdysteroids before culture in our conditions and did not store them during incubation. The amount of hormones was determined by comparison with dose-response curves using ecdysone as standard, this compound being the main ecdysteroid secreted by blowfly ovaries (unpublished observations). Consequently, the data were calculated as picograms ecdysone-equivalents per culture. The lower detection limit of our assay was about 1 pg per ovary.

cAMP was determined as previously described (Manière et al. 2000), from the acid extract of a single ovary, with the immunoassay described by Kingan (1989). Data are reported as fmol cAMP per ovary.

\section{Statistics}

For each individual experiment, the ratio of the concentration of ecdysone, or of cAMP, in the experiment over control was calculated and the data presented as relative means ( \pm S.E.M.). Such treated/control ratios are independent of the size of flies (or of ovaries) and from incubation times (see Manière et al. 2000 for more details). Statistical analysis was generally made using either Student's $t$-test, by comparing means of concentration ratios to the theoretical value of 1 (which is equivalent to a paired $t$-test), or, for multiple comparisons, one-way ANOVA.

\section{Results}

\section{Steroidogenic effects of bovine insulin in blowflies}

The ability of bovine insulin to stimulate ecdysteroid biosynthesis was first verified on isolated previtellogenic ovaries from 5-day-old blowflies. As outlined in Table 1, the secretion of ecdysteroids into the culture medium increased in the presence of $10^{-5} \mathrm{M}$ insulin by about $2 \cdot 5$-fold over their corresponding contralateral controls. By comparison, BSA at the same concentration was ineffective. Insulin at $10^{-6} \mathrm{M}$ or at lower concentrations had no significant effect. Due to the limited solubility of insulin under physiological $\mathrm{pH}$ conditions, concentrations higher than $10^{-5} \mathrm{M}$ insulin could not be tested.
Table 1 Effects of bovine insulin on ecdysteroid biosynthesis in isolated previtellogenic ovaries from 5-day-old female blowflies, after overnight incubation in vitro. Absolute amounts of ecdysteroids secreted by one ovary in control cultures after overnight incubation was $40 \cdot 9 \pm 6 \cdot 5$ pg ecdysone-equivalents $(n=20)$

Individual treated/control ratios $n$

\section{Experimental \\ treatments}

Null (blanks)

Insulin $\left(10^{-6} \mathrm{M}\right)$

Insulin $\left(10^{-5} \mathrm{M}\right)$
BSA $\left(10^{-5} \mathrm{M}\right)$ (means \pm S.E.M.)

$$
\begin{aligned}
& 0 \cdot 99 \pm 0 \cdot 08 \\
& 1 \cdot 08 \pm 0 \cdot 15 \\
& 1 \cdot 19 \pm 0 \cdot 09 \\
& 2 \cdot 44 \pm 0 \cdot 34 \text { * }
\end{aligned}
$$

*Result significantly different from the ideal value of 1 (Student's $t$-test, $P<0 \cdot 05)$.

The effects of $10^{-5} \mathrm{M}$ insulin were then examined at different days following adult ecdysis. As shown in Fig. 1, the steroidogenic properties of insulin were dependent on female age. In fact, insulin was unable to stimulate steroidogenesis in ovaries explanted during the 2 days following ecdysis, but ovaries progressively acquired the capacity to respond to insulin stimulation during the following days, reaching a plateau 5-6 days after ecdysis.

The capacity of ovaries to respond to insulin was not conditioned by a previous contact of females with males. Indeed, $10^{-5} \mathrm{M}$ insulin produced similar stimulatory effects on ovaries isolated from 5-day-old females previously maintained either in the presence or in the absence of males; treated/control ratios of ecdysteroid production by fly ovaries of a same batch were $2 \cdot 75 \pm 0 \cdot 45, n=6$, in the presence of males and $2 \cdot 80 \pm 0 \cdot 45, n=7$, in their

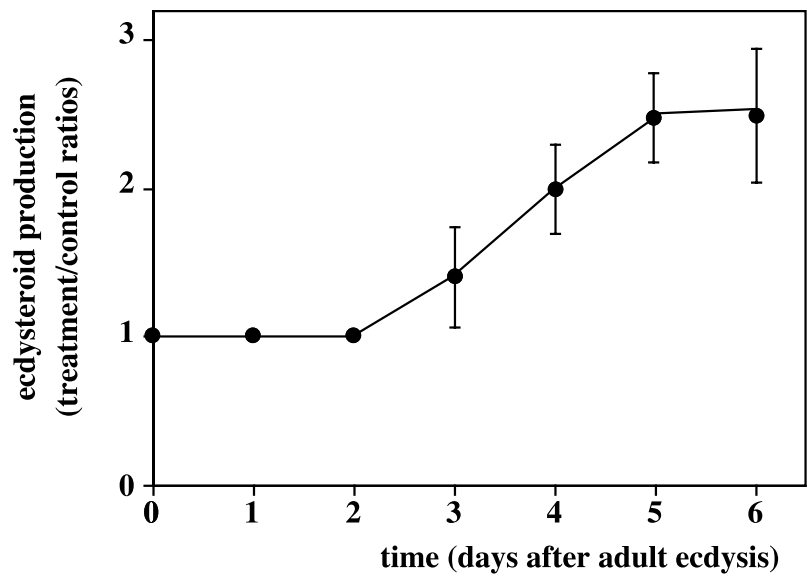

Figure 1 Progressive acquisition of the steroidogenic response to insulin $\left(10^{-5} \mathrm{M}\right)$ by previtellogenic ovaries isolated from Phormia at different days after adult ecdysis. Same experimental conditions as in Table 1. 
absence; these data were not significantly different when evaluated by Student's $t$-test $(P>0 \cdot 05)$.

\section{Insulin effects were not mediated by cAMP}

Surprisingly, the insulin-stimulated physiological properties reported above were very similar to those previously observed with cAMP-dependent steroidogenesis in our model (Manière et al. 2000). Thus it was important to evaluate if insulin treatment would cross-talk with the cAMP pathway. Concentrations of cAMP in isolated ovaries were determined after $1 \mathrm{~h}$ incubation with or without $10^{-5} \mathrm{M}$ insulin and no significant difference was observed (18.0 $\pm 3 \cdot 6$ and $16 \cdot 6 \pm 3 \cdot 1$ fmol cAMP per ovary respectively; $n=9, P>0 \cdot 05)$. Similar measurements were also made after the addition of 3-isobutyl-1methylxanthine (IBMX) at $10^{-3} \mathrm{M}$, a concentration known to inhibit phosphodiesterases and to enhance cAMP concentrations in our model (Manière et al. 2000, 2003). Results showed that insulin did not increase ovarian cAMP concentrations in the presence of IBMX $(28.4 \pm 5.0 \mathrm{fmol}$ cAMP in insulin-treated ovaries vs $27 \cdot 4 \pm 6 \cdot 1 \mathrm{fmol}$ in controls; $n=13, P>0 \cdot 05)$.

Moreover, experiments with the cAMP antagonist adenosine-3', 5'-cyclic monophosphorothioate, Rpisomer (Rp-cAMPS), used at doses known to be effective on cAMP-stimulated biosynthesis (Manière et al. 2000, 2002), did not decrease insulin-stimulated steroidogenesis. Amounts of ecdysteroids secreted by ovaries simultaneously treated with $10^{-5} \mathrm{M}$ insulin and with either $10^{-4} \mathrm{M}$ or $10^{-3} \mathrm{M}$ Rp-cAMPS $(64 \cdot 2 \pm 10 \cdot 4 \mathrm{pg}(n=4)$ and $72 \cdot 0 \pm 5 \cdot 1 \mathrm{pg}(n=6)$ respectively) were not significantly different from those secreted by ovaries treated with $10^{-5} \mathrm{M}$ insulin only $(63 \cdot 2 \pm 8 \cdot 2 \mathrm{pg} ; n=6, P>0.05)$, but were different from those of untreated controls $(28 \cdot 1 \pm 3 \cdot 1 \mathrm{pg} ; n=14, P<0 \cdot 05)$. Altogether, these experiments clearly demonstrated that the steroidogenic action of insulin was not mediated via the cAMP pathway.

\section{Effects of pharmacological compounds interfering with insulin signaling}

Pharmacological compounds mimicking insulin action in mammals were found to stimulate ovarian steroidogenesis in blowflies. In particular, $\mathrm{mpV}$ (pic), a potent inhibitor of protein phosphotyrosine phosphatase and activator of insulin receptor kinase (Posner et al. 1994), was found to stimulate ecdysteroid biosynthesis very efficiently in isolated ovaries; as shown in Fig. 2, a significant increase of steroidogenesis was observed with $10^{-4} \mathrm{M}$ and $10^{-3} \mathrm{M}$ $\mathrm{mpV}$ (pic). Moreover, okadaic acid, a known inhibitor of serine/threonine phosphatases, including those regulating the activity of protein kinase B (Haystead et al. 1990, Tanti et al. 1997), was also found to stimulate ovarian ecdysteroid biosynthesis significantly at concentrations higher or equal to $10^{-7} \mathrm{M}$ (treated/control ratio of $2 \cdot 24 \pm 0 \cdot 49$ at $\left.10^{-7} \mathrm{M} ; n=8, P<0 \cdot 05\right)$.

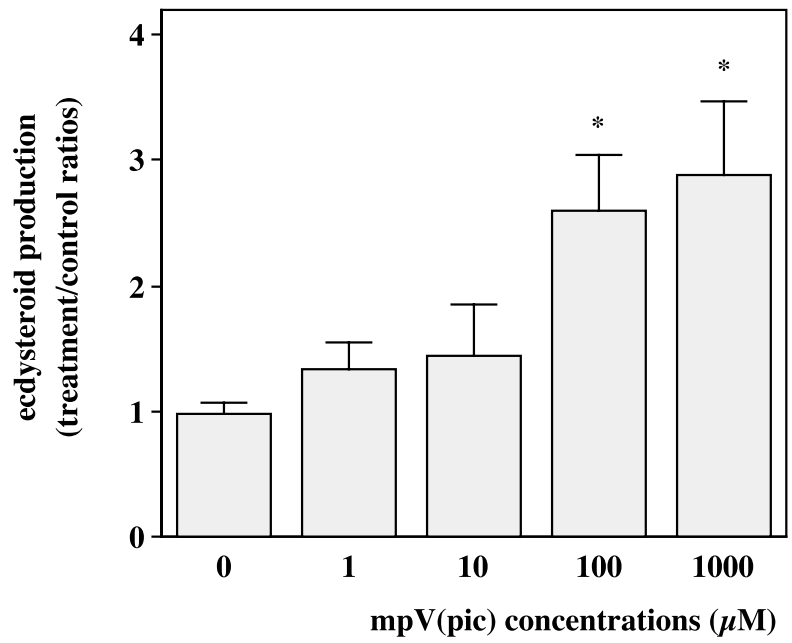

Figure 2 Effects of various concentrations of $\mathrm{mpV}$ (pic), a potent activator of mammalian insulin receptor, on steroidogenesis in blowfly previtellogenic ovaries. Each histogram bar, obtained from immunoassay measurements, represents the mean ( \pm S.E.M.) of 8-12 individual ratios; these ratios were calculated by dividing the ecdysteroid amounts secreted by one ovary, submitted to $\mathrm{mpV}$ (pic) (except for blanks at concentration 0), with those of the other ovary of the same pair, being the corresponding untreated control. *Results significantly different from the ideal value of 1 (Student's $t$-test, $P<0 \cdot 05$ ).

Conversely, pharmacological compounds having inhibitory effects on insulin signaling in mammals reduced insulin-stimulated ecdysteroid secretion in blowfly ovaries. This was observed with HNMPA-( $\mathrm{AM})_{3}$, a potent and specific inhibitor of insulin receptor tyrosine kinase (Saperstein et al. 1989). When used at $10^{-3} \mathrm{M}$, this compound almost completely inhibited the stimulation of steroidogenesis by insulin, but had no effect on basal steroidogenesis in the absence of insulin, and thus, no apparent toxicity (Table 2). The $\mathrm{IC}_{50}$ (concentration

Table 2 Effects of HNMPA-(AM) ${ }_{3}$, an inhibitor of insulin receptor tyrosine kinase, either used alone or in combination with $10^{-5} \mathrm{M}$ bovine insulin, on ecdysteroid production by isolated previtellogenic ovaries from 5-day-old female blowflies, after overnight incubation in vitro

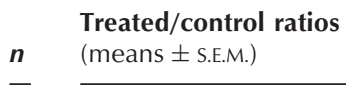

\section{Experimental}

treatments

Null (blanks)

HNMPA- $(\mathrm{AM})_{3}\left(10^{-4} \mathrm{M}\right)$

HNMPA- $(\mathrm{AM})_{3}\left(10^{-3} \mathrm{M}\right)$

Insulin alone

Insulin + $\mathrm{HNMPA}-(\mathrm{AM})_{3}\left(10^{-4} \mathrm{M}\right)$

Insulin + HNMPA- $(\mathrm{AM})_{3}\left(10^{-3} \mathrm{M}\right)$

(means \pm S.E.M.

* Result significantly different from the ideal value of 1 (Student's $t$-test $P<0 \cdot 05)$. 


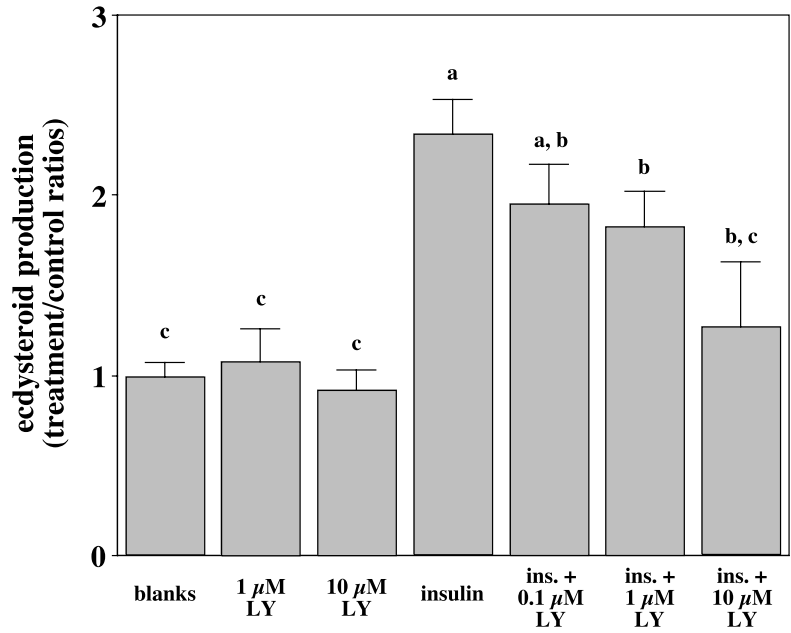

Figure 3 Effects of LY294002 (LY), a potent inhibitor of PI3K and of the insulin signaling pathway, on insulin-stimulated ovarian steroidogenesis. Production of ecdysteroids by untreated individual ovaries (blanks), by ovaries incubated only with 1 or $10 \mu \mathrm{M} \mathrm{LY}$, by ovaries incubated with $10^{-5} \mathrm{M}$ insulin, or by ovaries incubated simultaneously with $10^{-5} \mathrm{M}$ insulin (ins.) and with $0 \cdot 1,1$ or $10 \mu \mathrm{M}$ LY, was compared with corresponding controls and expressed as treated/control ratios. Each histogram (mean ratios \pm S.E.M.) was calculated from five to seven measurements. Same letters over error bars indicate values which were not significantly different (ANOVA, $P<0 \cdot 05$ ).

giving $50 \%$ of maximal inhibition) of this inhibitor ranged between $0 \cdot 1$ and $1 \mathrm{mM}$ in our model, which is higher than reported for mosquitoes $(14 \cdot 2 \mu \mathrm{M}$, Riehle \& Brown 1999), but seemed to be consistent with the concentration reported for vertebrates $(200 \mu \mathrm{M}$, Saperstein et al. 1989).

Inhibition of insulin-stimulated steroidogenesis was also observed with a specific inhibitor of phosphatidylinositol 3-kinase (PI3K), LY294002 (Vlahos et al. 1994). When administered alone, this compound had no effect, showing no apparent toxicity. However, in the presence of insulin, it was able to inhibit the hormonal stimulation of ovarian steroidogenesis in a dose-dependent manner (Fig. 3). Its $\mathrm{IC}_{50}$ was estimated to be in the range $1-3 \mu \mathrm{M}$ in our experiments, which is higher than the value reported in mosquitoes (30 nM, Riehle \& Brown 1999), but in better agreement with vertebrate studies $(1 \cdot 4 \mu \mathrm{M}$, Vlahos et al. 1994). A comparable inhibition of insulin-stimulated steroidogenesis was also observed with wortmannin, another inhibitor of PI3K (not shown). Altogether, these results corroborated the involvement of several components of the insulin transduction pathway during the stimulation of ovarian steroidogenesis.

\section{Insulin-like peptides from brain MNCs regulate ovarian steroidogenesis}

Previous studies have demonstrated that blowfly MNCs elaborate a neurohormonal factor able to stimulate ovarian

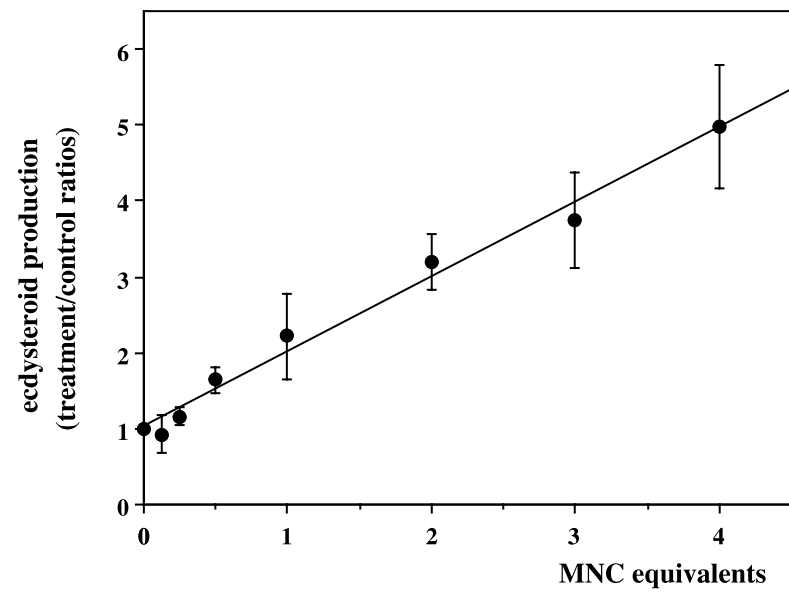

Figure 4 Stimulation of ecdysteroid biosynthesis in isolated previtellogenic ovaries by increasing quantities of crude extracts from blowfly MNCs, expressed in brain-equivalents per ovary. Each histogram was calculated from five to eight ovary pairs. Results obtained from 0.5 MNC-equivalents and more were significantly different from the ideal value of 1 (Student's $t$-test, $P<0 \cdot 05)$

steroidogenesis through a cAMP-independent pathway (Manière et al. 2000). Complementary experiments showed that MNC extracts were able to trigger ovarian steroidogenesis with a regular, almost linear, doseresponse curve within the range tested, allowing higher activation ratios than insulin (Fig. 4). As with insulin experiments, these results were obtained with ovaries extirpated 5 days after ecdysis, whereas those extirpated during the first two days remained insensitive to $\mathrm{MNC}$ extracts.

In order to verify that MNC gonadotropic activity could be due, at least in part, to an insulin-like neurohormone, ovaries were incubated with MNC extracts, in the presence or absence of the PI3K inhibitor LY294002. Results, given in Fig. 5, showed that LY294002 at $10^{-5} \mathrm{M}$ significantly attenuated MNC-stimulated steroidogenesis. These data indicate that PI3K is involved in the stimulation of ovarian steroidogenesis by $\mathrm{MNC}$ extracts. As this kinase is a key component of the insulin-like signaling pathway, our data corroborated the hypothesis that MNC activity was due to endogenous ILPs.

Since blowfly ILPs have not yet been isolated, bombyxin II, an ILP previously identified from silkworm MNCs and prepared by chemical synthesis, was studied in our in vitro assay. As outlined in Fig. 6, a micromolar concentration of bombyxin was able to stimulate steroidogenesis in blowfly ovaries significantly. Bombyxin was obviously more active than bovine insulin and allowed higher activation ratios, comparable with those obtained with MNC extracts. These results showed for the first time that an insect ILP is able to stimulate the ovarian biosynthesis of ecdysteroids. 


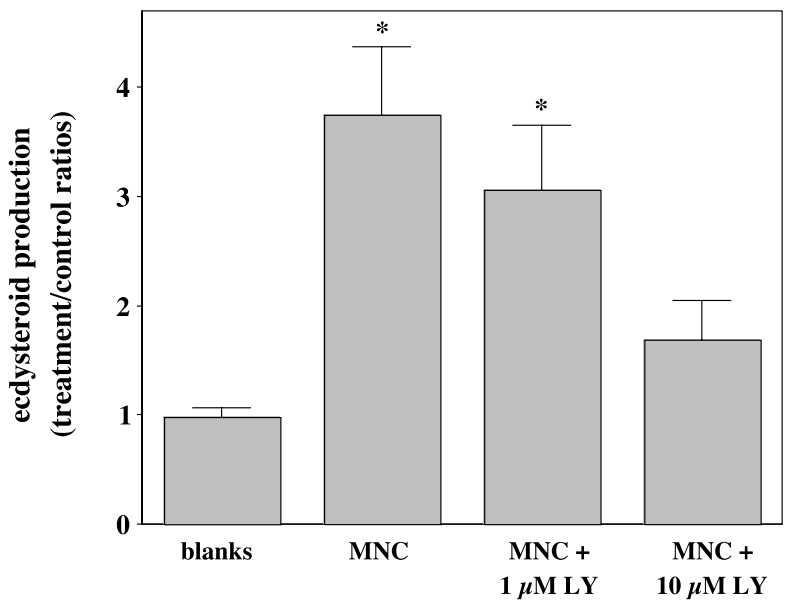

Figure 5 Inhibition of MNC-stimulated steroidogenesis (MNC, at a single concentration of 3 brain-equivalents) by the PI3K inhibitor LY294002 (LY) at two concentrations. See Fig. 3 for the effects of LY used alone at these concentrations. Each histogram was calculated from five to eight ovary pairs. *Results which are significantly different from the ideal value of 1 (Student's $t$-test, $P<0 \cdot 05)$.

\section{Discussion}

The physiological significance of the ovarian response to insulin

It is now well established that ILPs are important signaling molecules present in insects and in numerous other invertebrates (for review see Ebberink et al. 1989, Claeys et al. 2002, Nässel 2002). As in vertebrates, insect ILPs seem to control several interrelated, well-conserved functions (such as the regulation of growth, body size and metabolism or aging) and also play a role during reproduction (for review see Smit et al. 1998, Claeys et al. 2002,

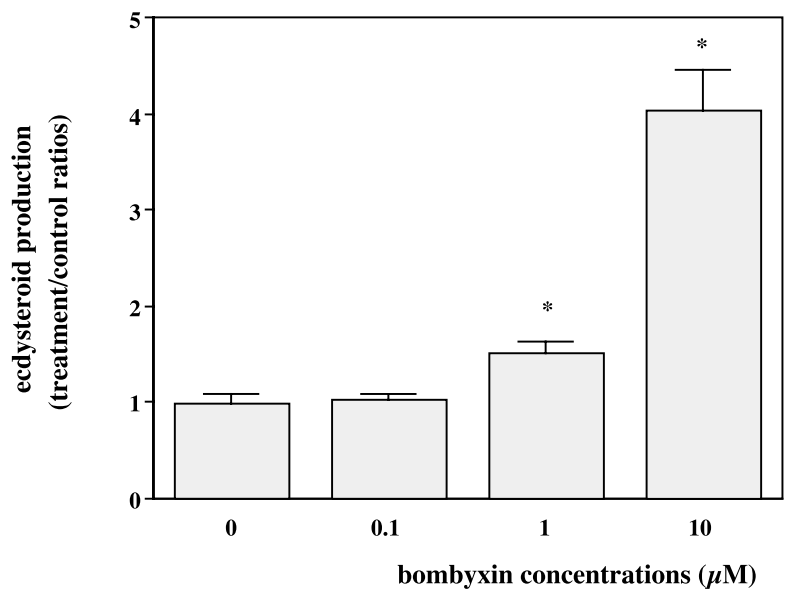

Figure 6 Stimulation of ovarian steroidogenesis by bombyxin II. Each histogram was calculated from seven or eight ovary pairs. * Results which are significantly different from the ideal value of 1 (Student's $t$-test, $P<0 \cdot 05$ ).
Garofalo 2002). Because of its discovery in silkworms (Nagasawa et al. 1986), the first ILP identified in insects was named bombyxin, but those found later have been more frequently designated according to their resemblance with the mammalian hormone. However, there is no argument indicating that bombyxins might not be homologous to other insect ILPs and the following discussion will thus consider that insect ILPs include bombyxins.

Several studies have also shown that insulin and/or insulin-like growth factors from mammals are able to elicit various physiological responses in insects (e.g. Bhakthan \& Gilbert 1968, Vanhems et al. 1990, Hatt et al. 1997), emphasizing some of the pleiotropic functions played by ILPs in animals. More particularly, investigations on the mosquito A. aegypti (Graf et al. 1997, Riehle \& Brown 1999) revealed ovarian steroidogenesis as a remarkable target of insulin in insects. Our present observations in blowflies are in perfect agreement with these reports and suggest that the steroidogenic property of insulin - and, probably, of endogenous ILPs - may be widespread in Diptera, if not in other insects.

However, the high concentration at which bovine insulin was active on blowfly ovaries could call into question the physiological significance of this response. Indeed, this concentration is an order of magnitude higher than the concentration active in mosquitoes (Graf et al. 1997) and both are higher than the physiological concentrations in mammals. However, these absolute concentrations of insulin are probably not very significant, since they probably result from a weaker affinity of blowfly receptors for the bovine peptide than for their natural ligands. This is substantiated by the results obtained with bombyxin and with MNC extracts, provided that the same receptors are involved in these different treatments (this will be discussed below). Indeed, bombyxin is an insect ILP and, in spite of the fact that it originates from a very distant species, it is more active than mammalian insulin. Moreover, extracts from blowfly MNCs, which most probably do not store large quantities of endogenous ILPs (the site of storage corresponding to corpora cardiaca being outside the brain), obviously acted at much lower and therefore physiologically more relevant concentrations.

Other results confirm that the response elicited by insulin has true physiological significance. In particular, the progressive appearance of insulin responsiveness in blowfly ovaries suggests that this property is precisely controlled over time. These data are in agreement with numerous reports that showed that the first 2 or 3 days following blowfly eclosion correspond to a progressive maturation of the whole reproductive system, under the control of corpora allata and/or of brain MNCs (Thomsen 1942, 1948, 1952, Thomsen \& Lea 1969, Pappas \& Fraenkel 1978, Yin et al. 1990). They are also in agreement with recent findings in mosquitoes, showing a 
progressive expression of ILP receptor in ovarian follicular cells during previtellogenesis (Riehle \& Brown 2002).

Interestingly, the activity of MNC extracts seemed to vary as a function of the age of ovaries, in a similar way to insulin. However, the sensitivity to cAMP-mimicking compounds also showed the same progressive responsiveness as insulin (Manière et al. 2000). These observations indicate that the responses to insulin and to endogenous ILPs have common physiological relationships with cAMP-dependent steroidogenesis. This could suggest that the receptors and/or the cellular components of the transduction pathways controlling ovarian steroidogenesis appear simultaneously and/or are regulated by the same factors. However, it may also indicate that common downstream effectors of these signaling pathways, in particular the biosynthetic enzymes, are developmentally controlled.

Our other results indicated that the sensitivity of blowfly ovaries to insulin is not directly controlled by factors depending on the presence of males. The insulin sensitivity of ovaries was indeed the same in virgin or in mated female blowflies. Here again, a similar observation has been made previously with the sensitivity to cAMPmimicking substances (Manière et al. 2000), which again substantiates that the insulin response has a physiological significance and possible relationships with cAMPdependent steroidogenesis.

\section{Mode of action of insulin and ILPS}

Several studies have emphasized that insects possess tyrosine kinase receptors displaying various similarities with mammalian insulin receptors (for review see Claeys et al. 2002, Garofalo 2002, Goberdhan \& Wilson 2003), so much so that they can be activated by bovine insulin (Fernandez-Almonacid \& Rosen 1987). They are frequently named 'insulin receptors', although the term 'ILP receptors' appears more appropriate in insects and will be preferred below. In lepidopterans, the bombyxin receptor has also shown similarities with the mammalian insulin receptor and can thus be considered as an ILP receptor (Fullbright et al. 1997). Interestingly, despite the presence of several different ILP genes, only one corresponding receptor gene has been identified so far in the genome of Drosophila and similar observations have been made in the other known invertebrate models, in contrast to what is described in vertebrates (for review see Nässel 2002, Goberdhan \& Wilson 2003). If a single receptor is also present in Phormia, it appears very likely that bovine insulin and bombyxin acted on blowfly ovaries through this receptor, also sensitive to endogenous ILP ligands from MNCs.

In adult insects, the ILP receptor is expressed essentially in the ovaries, in close correlation with ecdysteroidogenesis (Fullbright et al. 1997, Graf et al. 1997, Helbling \& Graf 1998, Riehle \& Brown 2002). Moreover, it has been demonstrated that ILP receptor is involved in the steroidogenic response of ovaries to insulin (Riehle \& Brown 1999, 2002, Tu et al. 2002). Our own experiments in blowflies are again in total agreement with these observations. Indeed, a potent and specific activator of insulin signaling in mammals, $\mathrm{mpV}(\mathrm{pic})$, a peroxovanadium compound inhibiting tyrosine kinase phosphatase and activating more specifically mammal insulin receptor (Posner et al. 1994), was found to stimulate ovarian steroidogenesis very efficiently in our model. This result confirms the observations made with another vanadate derivative in mosquitoes (Riehle \& Brown 1999). Reciprocally, a potent inhibitor of the mammal insulin receptor, such as HNMPA-(AM) ${ }_{3}$ (Saperstein et al. 1989), inhibited ecdysteroid production in our model, as also observed in the female mosquito (Riehle \& Brown 1999). Altogether, these experiments clearly indicated that the steroidogenic effect of bovine insulin is mediated by an ILP receptor.

Downstream of the receptor, the cellular signaling mechanisms triggered by ILPs in insects also appear to be very well conserved (for review see Smit et al. 1998, Claeys et al. 2002, Garofalo 2002). In particular, observations on mosquitoes (Riehle \& Brown 1999) have shown that ovarian steroidogenesis is controlled by a typical cascade of events involving a series of protein kinases, such as PI3K and protein kinase B (PKB). Using similar pharmacological experiments, our present observations are in absolute agreement with these findings. Indeed, the PI3K inhibitors LY294002 and wortmannin inhibited insulin-stimulated ovarian steroidogenesis in our model, indicating that PI3K plays an important role in the regulation of steroidogenesis by ILPs. Moreover, okadaic acid, a protein phosphatase inhibitor, was found to be an efficient activator of ecdysteroid biosynthesis in blowfly ovaries, which suggests the involvement of PKB. Indeed, okadaic acid is known to mimic insulin action when the inhibition of protein phosphatases favors the activation of PKB (Haystead et al. 1990, Tanti et al. 1997), in spite of possible inhibitory effects upstream from PKB (Mothe \& Van Obberghen 1996).

Although the pharmacological compounds used during this study appeared less efficient in blowflies than reported in mosquitoes (Riehle \& Brown 1999), the concentrations used in our model remained in agreement with those mentioned in vertebrate studies. More importantly, they were found to have no toxic effect, as judged by the fact that, when used alone, they did not decrease basal steroidogenesis, this parameter being easily measurable and extremely sensitive to any entry of calcium (Manière et al. 2002), which would be inevitable after cellular deteriorations. Thus, our observations corroborated that several components of the insulin-like signaling system, namely ILP receptor, PI3K and PKB, are involved in the control of ovarian steroidogenesis stimulated by bovine insulin in blowflies. 
However, the physiological characteristics of insulindependent steroidogenesis in blowfly ovaries also showed striking similarities with those previously observed for cAMP-dependent biosynthesis of ovarian ecdysteroids (Manière et al. 2000). It was then easily conceivable that the insulin signaling pathway could have an indirect influence on cAMP metabolism, causing the cAMP pathway to mediate insulin action ultimately. Examples of such an indirect action of insulin have been found in vertebrates as well as in invertebrates (Kuznetsova et al. 1999, Plesneva et al. 2001, Shpakov et al. 2002). In our model, however, bovine insulin did not increase the ovarian concentrations of cAMP and, furthermore, an efficient cAMP antagonist failed to prevent it stimulating ovarian steroidogenesis. Thus it seems definitely established that insulin-induced ovarian steroidogenesis in blowflies is a cAMPindependent process.

\section{ILPs as potential steroidogenic gonadotropins in insects}

Numerous reports have indicated that MNCs play an important role during the reproduction of insects (Thomsen 1948, Girardie 1983). The presence of insulinlike material in insect brain, and particularly in MNCs, has been detected in various species, including blowflies (e.g. Tager et al. 1976, Duve \& Thorpe 1979, Duve et al. 1979). More recently, different ILPs encoded by different genes were described for Bombyx (Kondo et al. 1996) and Drosophila (Brogiolo et al. 2001). These genes have different time patterns of expression in MNCs and, therefore, different putative functions.

In spite of the wealth of arguments suggesting a possible involvement of ILPs from MNCs during insect reproduction (see Introduction), no direct evidence has been obtained before this study showing that ILPs could really regulate ovarian ecdysteroidogenesis. Consequently, they are generally not considered gonadotropins (see a recent review on gonadotropins in De Loof et al. 2001). On the contrary, the only neurohormones that have been identified as insect gonadotropins (i.e. OMP and $\mathrm{OEH}$ ), although originating from MNCs, are not ILPs (Girardie \& Girardie 1996, Brown et al. 1998). In mammals, insulin and/or insulin-like growth factors also modulate ovarian steroidogenesis and are not considered to be steroidogenic hormones or gonadotropins. In this case, however, they are generally supposed to act by potentiating the steroidogenic response of ovaries to pituitary gonadotropins, without having effects on their own (for review see Poretsky et al. 1999).

In contrast, our experiments provide two pieces of evidence that ILPs originating from MNCs are direct activators of steroidogenesis in blowfly ovaries and then, may be considered as potential gonadotropins. The first evidence is given by experiments showing that extracts from blowfly MNCs are able to stimulate ovarian steroido- genesis very efficiently and that this stimulation can be prevented by an inhibitor of PI3K, a key component of the mammalian insulin signaling pathway. These findings complete our previous study showing that the gonadotropic action of MNCs is cAMP independent (Manière et al. 2000), as also demonstrated in this study for insulin. Altogether, these results indicate that MNC extracts may stimulate ovarian steroidogenesis by acting mainly, if not only, through the ILP signaling pathway and, consequently, that the activity of these extracts is probably due to endogenous ILPs.

The second evidence is that synthetic bombyxin, an ILP originating from silkworm MNCs, is able to stimulate ovarian steroidogenesis in blowflies. Although the mode of action of bombyxin has not been investigated in our model, it has been clearly shown that it acts through an ILP receptor in lepidopterans (Fullbright et al. 1997). Since bombyxin has the same effect as bovine insulin and as MNC extracts in our model, it seems very probable that it is able to bind to the same receptor and to stimulate steroidogenesis through the same pathway.

Taking in account that bombyxin is originating from a distant species, the question is raised of the possible extent of the gonadotropic role of ILPs in insects. Other experiments indicate that ILPs extracted from Locusta, which are active in our blowfly model, are also able to stimulate ovarian steroidogenesis in locusts (Delbecque et al., unpublished observations), corroborating the possibility of a steroidogenic role of ILPs in the ovaries of very different groups of insects. Moreover, as bombyxin is also a regulator of steroidogenesis in larval molting glands (Nagasawa et al. 1986), ILPs could participate in the control of ecdysteroid biosynthesis during both the development and the reproduction of insects, in synergy with prothoracicotropic hormone $(\mathrm{PTTH})$ in larvae or with the cAMPgenerating factor present in adults (see Manière et al. 2000).

Finally, it seems possible that many of the effects attributed to ILPs in insects may be mediated by ecdysteroids during their reproduction cycles but possibly also during their whole life. This interpretation may lead to a re-examination of the relationships between ILPs and ecdysteroids, for example in the control of metabolism, of body size or in life-span regulation (see for example Simon et al. 2003 and Tatar et al. 2003), particularly when ILPs and ecdysteroids are obviously involved in the control of the same functions.

\section{Acknowledgements}

We are indebted to Drs M De Reggi (Marseille) and T Kingan (Riverside, California, USA) for the gift of antibodies or reagents for immunoassays. We also thank $\mathrm{Cl}$. Renouleaud for her valuable technical help. 


\section{Funding}

This study was supported by Université Bordeaux I, by CNRS (ER CNRS 629) and by the National Science Foundation (grant MCB 94-06656 to EEB). The authors declare that no competing financial interest has been prejudicial to the impartiality of this research.

\section{References}

Bhakthan NM \& Gilbert LI 1968 Effects of some vertebrate hormones on lipid mobilization in the insect fat body. General and Comparative Endocrinology 11 186-197.

Brogiolo W, Stocker H, Ikeya T, Rintelen F, Fernandez R \& Hafen E 2001 An evolutionarily conserved function of the Drosophila insulin receptor and insulin-like peptides in growth control. Current Biology 11 213-221.

Brown MR, Graf R, Swiderek KM, Fendley D, Strackert TH, Champagne DE \& Lea AO 1998 Identification of a steroidogenic neurohormone in female mosquitoes. Journal of Biological Chemistry 273 3967-3971.

Büllesbach EE 1999 Bombyxin exhibits an insulin-like response to modification in the $\mathrm{N}$-terminal region of the A chain. Journal of Peptide Research 54 12-17.

Chavez VM, Marques G, Delbecque JP, Kobayashi K, Hollingsworth M, Burr J, Natzle JE \& O'Connor MB 2000 The Drosophila disembodied gene controls late embryonic morphogenesis and codes for a cytochrome P450 enzyme that regulates embryonic ecdysone levels. Development 127 4115-4126.

Claeys I, Simonet GJP, Van Loy T, Vercammen L, De Loof A \& Vanden Broeck J 2002 Insulin-related peptides and their conserved signal transduction pathway. Peptides 23 807-816.

De Loof A, Baggerman G, Breuer M, Claeys I, Cerstiaens A, Clynen E, Janssen T, Schoofs L \& Vanden Broeck J 2001 Gonadotropins in insects: an overview. Archives of Insect Biochemistry and Physiology 47 $129-138$.

Duve H \& Thorpe A 1979 Immunofluorescent localization of insulin-like material in the median neurosecretory cells of the blowfly, Calliphora vomitoria (Diptera). Cell and Tissue Research 200 187-191.

Duve H, Thorpe A \& Lazarus NR 1979 Isolation of material displaying insulin-like immunological biological activity from the brain of the blowfly Calliphora vomitoria. Biochemical Journal $\mathbf{1 8 4}$ 221-227.

Ebberink RHM, Smit AB \& Van Minnen J 1989 The insulin family: evolution of structure and functions in vertebrates and invertebrates. Biological Bulletin 177 176-182.

Fernandez-Almonacid R \& Rosen OM 1987 Structure and ligand specificity of the Drosophila melanogaster insulin receptor. Molecular and Cellular Biology 7 2718-2727.

Fullbright G, Lacy ER \& Büllesbach EE 1997 The prothoracicotropic hormone bombyxin has specific receptors on insect ovarian cells. European Journal of Biochemistry 245 774-780.

Garofalo RS 2002 Genetic analysis of insulin signaling in Drosophila. Trends in Endocrinology and Metabolism 13 156-162.

Girardie A 1983 Neurosecretion and reproduction. In: Endocrinology of Insects, pp 305-317. Eds RGH Downer \& H Laufer. New York: Alan R Liss.

Girardie J \& Girardie A 1996 Lom OMP, a putative ecdysiotropic factor for the ovary in Locusta migratoria. Journal of Insect Physiology 42 215-221.

Girardie J, Geoffre S, Delbecque JP \& Girardie A 1998 Arguments for two distinct gonadotropic activities triggered by different domains of the ovary maturating parsin of Locusta migratoria. Journal of Insect Physiology 44 1063-1071.
Goberdhan DC \& Wilson C 2003 The functions of insulin signaling: size isn't everything, even in Drosophila. Differentiation 7, 375-397.

Goltzené F, Lagueux M, Charlet M \& Hoffmann JA 1978 The follicle cell epithelium of maturing ovaries of Locusta migratoria : a new biosynthetic tissue for ecdysone. Hoppe-Seyler's Zeitschrift für physiologishes Chemie 359 1427-1434.

Graf R, Neuenschwander S, Brown MR \& Ackermann U 1997 Insulin-mediated secretion of ecdysteroids from mosquito ovaries and molecular cloning of the insulin receptor homologue from ovaries of bloodfed Aedes aegypti. Insect Molecular Biology 6 151-163.

Hagedorn H 1989 Physiological roles of hemolymph ecdysteroids in the adult insect. In: Ecdysone: From Chemistry to Mode of Action, pp 279-289. Ed J Koolman. Stuttgart: Georg Thieme Verlag.

Hatt PJ, Liebon C, Moriniere M, Oberlander H \& Porcheron P 1997 Activity of insulin growth factors and shrimp neurosecretory organ extracts on a lepidopteran cell line. Archives of Insect Biochemistry and Physiology 34 313-328.

Haystead TA, Weiel JE, Litchfield DW, Tsukitani Y, Fischer EH \& Krebs EG 1990 Okadaic acid mimics the action of insulin in stimulating protein kinase activity in isolated adipocytes. The role of protein phosphatase $2 \mathrm{a}$ in attenuation of the signal. Journal of Biological Chemistry 265 16571-16580.

Helbling P \& Graf R 1998 Localization of the mosquito insulin receptor homolog (MIR) in reproducing yellow fever mosquitoes (Aedes aegypti). Journal of Insect Physiology 44 1127-1135.

Kingan TG 1989 A competitive enzyme-linked immunosorbent assay: applications in the assay of peptides, steroids and cyclic nucleotides. Analytical Biochemistry 183 283-289.

Kondo H, Ino M, Suzuki A, Ishizaki H \& Iwami M 1996 Multiple gene copies for bombyxin, an insulin-related peptide of the silkmoth Bombyx mori: structural signs for gene rearrangement and duplication responsible for generation of multiple molecular forms of bombyxin. Journal of Molecular Biology 259 926-937.

Kuznetsova L, Plesneva S, Derjabina N, Omeljaniuk E \& Pertseva M 1999 On the mechanism of relaxin action: the involvement of adenylyl cyclase signalling system. Regulatory Peptides 80 33-39.

Manière G, Vanhems E \& Delbecque JP 2000 Cyclic AMP-dependent and independent stimulations of ovarian steroidogenesis by brain factors in the blowfly, Phormia regina. Molecular and Cellular Endocrinology 168 31-40.

Manière G, Vanhems E, Gautron F \& Delbecque JP 2002 Calcium inhibits ovarian steroidogenesis in the blowfly Phormia regina. Journal of Endocrinology 173 533-544.

Manière G, Vanhems E, Gautron F \& Delbecque JP 2003 Inhibition of ovarian steroidogenesis by cyclic-GMP in a fly. Journal of Endocrinology 177 35-44.

Mothe I \& Van Obberghen E 1996 Phosphorylation of insulin receptor substrate- 1 on multiple serine residues, $612,632,662$, and 731, modulates insulin action. Journal of Biological Chemistry 271 11222-11227.

Nagasawa H, Kataoka H, Isogai A, Tamura S, Suzuki A, Mizoguchi A, Fujiwara Y, Suzuki A, Takahashi S \& Ishizaki H 1986 Amino acid sequence of a prothoracicotropic hormone of the silkworm Bombyx mori. PNAS 83 5840-5843.

Nässel DR 2002 Neuropeptides in the nervous system of Drosophila and other insects: multiple roles as neuromodulators and neurohormones. Progress in Neurobiology 68 1-84.

Pappas C \& Fraenkel G 1978 Hormonal aspects of oögenesis in the flies Phormia regina and Sarcophaga bullata. Journal of Insect Physiology 24 75-80.

Pascual N, Bellés X, Delbecque JP, Hua YJ \& Koolman J 1995 Quantification of ecdysteroids by immunoassay: comparison of enzyme immunoassay and radioimmunoassay. Zeitschrift für Naturforschung [C] $\mathbf{5 0} 862-867$.

Plesneva SA, Shpakov AO, Kuznetsova LA \& Pertseva MN 2001 A dual role of protein kinase $\mathrm{C}$ in insulin signal transduction via adenylyl cyclase signaling system in muscle tissues of vertebrates and invertebrates. Biochemical Pharmacology 61 1277-1291. 
Poretsky L, Cataldo NA, Rosenwaks Z \& Giudice LC 1999 The insulin-related ovarian regulatory system in health and disease. Endocrine Reviews 20 535-582.

Posner BI, Faure R, Burgess JW, Bevan AP, Lachance D, Zhang-Sun G, Fantus IG, Ng JB, Hall DA, Lum BS \& Shaver A 1994 Peroxovanadium compounds. A new class of potent phosphotyrosine phosphatase inhibitors which are insulin mimetics. Journal of Biological Chemistry 269 4596-4604.

Riehle MA \& Brown MR 1999 Insulin stimulates ecdysteroid production through a conserved signaling cascade in the mosquito Aedes aegypti. Insect Biochemistry and Molecular Biology 29 855-860.

Riehle MA \& Brown MR 2002 Insulin receptor expression during development and a reproductive cycle in the ovary of the mosquito Aedes aegypti. Cell and Tissue Research 308 409-420.

Saperstein R, Vicario PP, Strout HV, Brady E, Slater EE, Greenlee WJ, Ondeyka DL, Patchett AA \& Hangauer DG 1989 Design of a selective insulin receptor tyrosine kinase inhibitor and its effect on glucose uptake and metabolism in intact cells. Biochemistry $\mathbf{2 8}$ 5694-5701.

Sevala VM \& Loughton BG 1992 Insulin-like peptides during oogenesis and embryogenesis in Locusta migratoria. Invertebrate Reproduction and Development 21 187-192.

Shpakov AO, Plesneva SA, Kuznetsova LA \& Pertseva MN 2002 Study of the functional organization of a novel adenylate cyclase signaling mechanism of insulin action. Biochemistry (Mosc) 67 335-342.

Simon AF, Shih C, Mack A \& Benzer S 2003 Steroid control of longevity in Drosophila melanogaster. Science 299 1407-1410.

Smit AB, Vankesteren RE, Li KW, Vanminnen J, Spijker S, Vanheerikhuizen H \& Geraerts W 1998 Towards understanding the role of insulin in the brain: lessons from insulin-related signaling systems in the invertebrate brain. Progress in Neurobiology 54 35-54.

Tager HS, Markese J, Kramer KJ, Speirs RD \& Childs CN 1976 Glucagon-like and insulin-like hormones of the insect neurosecretory system. Biochemical Journal 156 515-520.
Tanti JF, Grillo S, Gremeaux T, Coffer PJ, Van Obberghen E \& Le Marchand-Brustel Y 1997 Potential role of protein kinase B in glucose transporter 4 translocation in adipocytes. Endocrinology 138 2005-2010.

Tatar M, Bartke A \& Antebi A 2003 The endocrine regulation of aging by insulin-like signals. Science 299 1346-1351.

Thomsen E 1942 An experimental and anatomical study of the corpus allatum in the blowfly, Calliphora erythrocephala Meig. Videnskabelige Meddelelser fra Dansk Naturhistorik Forening, Kobenhavn 106 320-405.

Thomsen E 1948 Effect of removal of neurosecretory cells in the brain of adult Calliphora erythrocephala Meig. Nature $\mathbf{1 6 1} 439$.

Thomsen E 1952 Functional significance of the neurosecretory brain cells and the corpus cardiacum in the female blowfly, Calliphora erythrocephala Meig. Journal of Experimental Biology 29 137-172.

Thomsen E \& Lea AO 1969 Control of the medial neurosecretory cells by the corpus allatum in Calliphora erythrocephala. General and Comparative Endocrinology 12 51-57.

Tu MP, Yin CM \& Tatar M 2002 Impaired ovarian ecdysone synthesis of Drosophila melanogaster insulin receptor mutants. Aging Cell 1 158-160.

Vanhems E, Delbos M \& Girardie J 1990 Insulin and neuroparsin promote neurite outgrowth in cultured locust CNS. European Journal of Neurosciences 2 776-782.

Vlahos CJ, Matter WF, Hui KY \& Brown RF 1994 A specific inhibitor of phosphatidylinositol 3-kinase, 2-(4-morpholinyl)-8-phenyl-4H-1-benzopyran-4-one (LY294002). Journal of Biological Chemistry 269 5241-5248.

Yin CM, Zou BX, Yi SX \& Stoffolano JG 1990 Ecdysteroid activity during oögenesis in the black blowfly, Phormia regina (Meigen). Journal of Insect Physiology 36 375-382.

Received 6 November 2003

Accepted 18 December 2003 